\title{
EL MEDITERRÁNEO A TRAVÉS DE LA FICCIÓN: EL EXTRAÑO CASO DE SIR JOHN MANDEVILLE
}

\author{
SusAna MORALES OSORIO \\ Universidad de Granada \\ SONIA FERNÁNDEZ HOYOS \\ Universidad de Granada
}

Resumen: Los viajes de Sir John Mandeville presenta la construcción ficticia del Oriente a través de un relato de viajes que se configura en primera instancia como una peregrinación a Jerusalén. La concepción del viaje a través de la peregrinatio medieval, el homo viator como consecuencia del devenir religioso que empaña la Edad Media, la Biblia como geografía del mundo conocido y como destino de la curiosidad medieval, tienen en la figura narrativa del Libro de las Maravillas del Caballero Sir John Mandeville una de sus mejores articulaciones, al margen de los problemas y discusiones derivados de la existencia o no del autor. Por otro lado, el relato muestra una especial elaboración del Otro, de lo desconocido, a través de una mirada mítica, es decir, mediante la recreación de un fascinante conjunto de mirabilia que continúa sorprendiendo al lector actual.

Palabras clave: Literatura Inglesa, Edad Media, Literatura Comparada, Libros de viaje, Orientalismo.
Abstract: The Travels of Sir John Mandeville presents the ficticious construction of the Orient through a travels tale which is primarily shaped as a pilgrimage to Jerusalem. Over and above the critical controversy about the existence of Sir John Mandeville, this book depicts in a very accurate way several key topics in the literature of the Middle Ages as it is the conception of the travel through the medieval peregrination, the homo viator as a consequence of the religious becoming which steamed the Middle Ages, or the Bible as the geography of the known world and the destination of the medieval curiosity. On the other hand, the tale shows a very special devising of the Other, of the unknown, by means of a mythical perspective, that is, through the recreation of fascinating mirabilia collection that still impress the current reader.

Keywords: English Literature, Middle Age, Comparative Literature, Travel Books, Orientalism. 
El texto titulado Los viajes de Sir John Mandeville (o como también se ha venido traduciendo El Libro de las Maravillas del mundo), escrito circa 1356, ha constituido un enigma por cuanto a la recepción académica se refiere. La paradoja del texto es digna de mención aquí y ha sido destacada incansablemente por la crítica -más bien escasa - interesada en este objeto de estudio. Si bien Los viajes de Sir John Mandeville supuso un éxito absoluto en cuanto a popularidad desde que fue escrito a mediados del siglo XIV y hasta el XVI - éxito sólo superado en ese momento y en el occidente cristiano por la Biblia-; el interés crítico no fue parejo. Ya en el siglo XIX algunos estudiosos "descubrieron", para mayor horror y desencanto de la Academia, que los datos aportados por el prólogo y el epílogo no eran del todo ciertos. Vayamos al texto:

[...] y puesto que muchos hombres desean oír hablar de la Tierra Santa y de ello sacan solaz y consuelo, yo, John Mandeville, Caballero, aunque no me lo merezca, que nací en Inglaterra en la ciudad de Saint Albans, crucé el mar en el año de Nuestro Señor Jesucristo 1322, el día de San Miguel, y a partir de esa fecha he pasado largo tiempo en el mar y he recorrido muchas tierras diferentes, muchas provincias, reinos e islas [...] De tales tierras e islas hablaré más detalladamente, después. Y a su debido tiempo os describiré, según se me vayan ocurriendo, algunas de las cosas que existen allí. Y especialmente a aquellos que desean y tienen la intención de visitar la ciudad santa de Jeusalén y los santos lugares de los alrededores, les indicaré el camino que deben tomar para ir. Pues yo he hecho y recorrido ese camino muchas veces en la buena compañía de muchos señores. Gracias sean dadas a Dios!

Debéis saber que he traducido este libro del latín al francés, y lo he traducido de nuevo del francés al inglés para que todos los hombres de mi país puedan entenderlo. Pero los señores y caballeros, y otros nobles y hombres resptetables que no saben mucho latín y han estado en ultramar, puedan conocer y saber si digo o no la verdad, y si me equivoco en la descripción, por olvido o por alguna otra causa, pueden rectificarla y corregirla. Porque las cosas que sucedieron hace largo tiempo ante la mente y la vista de un hombre pasan pronto al olvido, pues 
la mente del hombre no puede comprender ni retener todo, a causa de la fragilidad humana"1 . (pp. 57-58).

Estas palabras preliminares habían sido consideradas ciertas y las investigaciones acerca de otros libros de viajes coetáneos al del supuesto autor John Mandeville demostraron que el autor había escrito su libro "sin salir de casa", aunque con una biblioteca a su alcance ${ }^{2}$. A partir de estas investigaciones, se abre un debate que se prolonga en el siglo $X X$, quién fue el verdadero autor: un físico llamado Jean de Bourgogne (o Jean à la Barbe, que murió en Liège en 1372), Jean d'Outremeuse (un notario también de Liège y cronista, que sería el primer responsable en la asociación de Jean de Bourgogne con Mandeville's Travels)... Y así se llega también a cuestionar la autenticidad de los orígenes: inglés, belga...

Se trata, pues, de un problema de lectura, de recepción: qué se espera del texto, qué expectativas quedan frustradas por un descubrimiento de tales características y, sobre todo, cómo se lee en el siglo XIX. Porque para estos

${ }^{1}$ La ediciones que manejamos y a la que irán referidas todas las citas del texto son de Ana PINTO, ed y trad. Los viajes de Sir John Mandeville, Madrid Cátedra, 2001. (Letras Universales 319) y Marie-José LEMARCHAND ed. y trad.: Libros de Maravillas. Benedeit y Mandeville, Madrid, Siruela, 2002. (Biblioteca Medieval).

${ }^{2}$ M.C. SEYMOUR enumera las siguientes fuentes que el "autor mandeviliano" utilizó en la compilación del libro, en las que suele estar de acuerdo la crítica:

-William of RUBRUCK: Historia Mongolorum (1255)

-Marco Polo: Le divisament dou Monde (1299)

[irrefutables]

XII-XIII

-Albert of AIX: HIstoria Hierosolimitana, 1125

-Brunetto LATINI: Le livre dou tresor, c. 1264

-Jacques de VORAGINE: Legenda aurea, c. 1275

-Jacques de VITRY: Historia Hierosolimitana, antes1240

-PSEUDO-ODORIC: De terra sancta, c. 1250

-Letter of Prester JOHN, c. 1250

-Peter COMESTOR: Historia scholastica, antes 1179

-Vincent of BEAUVAIS: Speculum historiale, c. 1250

-John SACROBOSCO: De sphera, c. 1220

-William of TRIPOLI: De statu Saracenorum, 1270 XIV

-Directorium ad faciendum passagium transmarinum, c. 1330

-HAITON: La flor des estoires de la terre d'Orient, antes 1308

-ODORIC: Itinerarius, 1330

-William of BOLDENSELE: Itinerarium, 1337

M.C.SEYMour: "Sir John Mandeville", en Authors of the Middle Ages 1, English Writers of the Late Middle Age,. Brookfield, Vermont: Variorum, 1993, pp. 12-13. 
críticos decimonónicos ${ }^{3}$ la validez del texto vendría legitimada por la experiencia del sujeto, experiencia propia de un viajero, de primera mano, que luego es capaz de consignarlo por escrito. Por eso, Tamarah Kohanski cuenta que, cuando estos críticos descubrieron que todo lo narrado procedía de fuentes previas y que el "itinerario" mandevilliano no era más que la suma o aglomeración de itinerarios de numerosos peregrinos y otros viajeros, y, para colmo, que quizá ni siquiera fuese inglés en absoluto, "they cried "Liar!"4 (p. 119). Es decir, lo que están proyectando desde ese paradigma crítico es un modelo de conocimiento ajeno al del propio texto y que no funciona dentro del mismo, puesto que el concepto mismo de autor que manejan nada tiene que ver con el texto medieval.

En cierto modo, la historia del manuscrito y luego del impreso, su tradición, supone que los libros tienen lectores pero no tienen autores o, más exactamente, no entran en su dominio de competencia. Así, para la historia del libro lo decisivo es su técnica, no el productor del texto; la atención al funcionamiento interno del sistema que propone el texto y no su inscripción en $s u$ historia. Sin embargo, con la Rezeptionstheorie $e^{5}$, se trata de caracterizar la relación dialógica entre una obra singular, en nuestro caso Los viajes de Sir John Mandeville, y el "horizonte de expectativa" de sus lectores en los distintos momentos históricos.

El conjunto de convenciones y referencias compartido por un público o públicos, lejos de ser considerado estable, unívoco o universal, es siempre histórico o históricamente construido, producido en la diferencia que separa las propuestas de la obra - controladas en parte por las intenciones del autor-

${ }^{3}$ Hablamos de E. B. NiCHOLSON, Henry Yule, Albert BovenSCHEN y George WARNER, por ejemplo, que leyeron el libro en su más estricto modelo histórico y geográfico.

${ }^{4}$ Tamarah KoHANSKI, "What is a 'travel book' anyway?: Generic Criticism and Mandeville's Travels", "LIT", vol. 7, pp. 117-130.

${ }^{5}$ Una bibliografía inmensa, pero para lo que sigue, hemos tenido en cuenta a Hans-Robert JAUSS, La literatura como provocación, Barcelona: Península, 1976; José Antonio MAYORAL ed., Estética de la recepción, Madrid, Arco Libros, 1987; Rainer WARNING, Estética de la recepción. Madrid, Visor, 1989; y, sobre todo, Michel FoUCAULT y su artículo Qu'est-ce qu'un auteur?, "Bulletin de la Societé française de Philosophie", 3 (julio-septiembre de 1969), pp. 73-104; posteriormente en 1970 imparte una versión modificada de esta conferencia que se publicó en 1979 en los Estados Unidos y, de nuevo, en 1983 autorizó una reedición de este texto para el "Bulletin de la Societé française de Philosophie". Hay versión española en Miguel MoREY, trad. y selección: Entre filosofía y literatura, Barcelona, Paidós, 1999, pp. 329-360. 
y las respuestas de los lectores. Con el New Historicism, se llega a situar la denominada obra literaria en su relación con los textos ordinarios (prácticos, jurídicos, políticos, religiosos, etc.) que constituirían el material sobre el que trabaja la escritura y que establece la posibilidad de su inteligibilidad. Con la sociología de la producción cultural, apoyada básicamente en las nociones de Pierre Bourdieu ${ }^{6}$, el análisis se desplaza hacia las leyes de funcionamiento y de jerarquías propias de un campo dado (literario o artístico, universitario, político, etc.), a las condiciones sociales de la producción del texto. Incluso se centra la atención, o podría, en las formas físicas a través de las cuales se transmiten los textos a sus lectores o a sus oyentes y en cómo afectan al proceso de construcción del sentido.

A pesar de las fuertes diferencias o divergencias, todos estos enfoques tienen un punto en común: volver a articular el texto con un autor, vincular el texto con la voluntad o la posición de su productor. En nuestro caso, no se trata de la restauración de la figura clásica, soberbia o solitaria, del autor soberano cuya intención (primera o última) encierra la significación de la obra y cuya biografía ordena la escritura en una transparente inmediatez. El autor (o autores) es a un tiempo dependiente y coaccionado. Dependiente porque no es el dueño del sentido, y sus intenciones, que portan la producción del texto, no se imponen necesariamente ni a quienes hacen de ese texto un libro (escribanos, libreros-editores u obreros impresores), ni a los que se lo apropian mediante su lectura. Coaccionado porque padece las múltiples determinaciones que organizan el espacio social de la producción literaria y las experiencias que son las matrices mismas de la escritura.

En el fondo, claro está, aparece Foucault cuando distinguía del "análisis histórico-sociológico del personaje del autor" un problema más fundamental: el de la construcción misma de una función-autor, considerada como una función clasificadora mayor de los discursos. Lejos de ser universal o pertinente para todos los textos en todas las épocas, la asignación de las obras a un nombre propio es considerada por Foucault como discriminadora: sólo válida para ciertas clases de textos: "la función-autor es característica del modo de existencia, circulación y funcionamiento de ciertos discursos en el

${ }^{6}$ Vid. Pierre BouRdiEU, especialmente, Las reglas del arte: génesis y estructura del campo literario, Barcelona, Anagrama, 1995. 
seno de una sociedad", y supone un estado de derecho que reconoce la responsabilidad penal del autor y el concepto de propiedad literaria: "la función-autor está ligada al sistema jurídico e institucional que encierra, determina y articula el universo de los discursos".

Así pues, a distancia de la evidencia empírica según la cual todo texto tiene un redactor, la definición de la función-autor es el resultado de "operaciones específicas y complejas" que refieren la inscripción histórica, la unidad y la coherencia de una obra a la identidad de un sujeto construido. Por eso, se puede negar incluso la existencia de Sir John Mandeville, esa identidad que ha constituido un misterio desde el siglo XIX hasta hoy, y el texto sigue funcionando. De hecho es lo que hacen algunos críticos, tal como recoge Ana Pinto en la introducción a su edición de Los viajes....

Sir John Mandeville nunca existió y su nombre sólo responde al de un personaje de ficción tras el cual escondió su identidad el verdadero autor de la obra, quien consiguió, en palabras de la Cambridge History of English Literature, "el fraude literario más logrado de la historia en uno de los libros más deliciosos que jamás se hayan escrito" (p. 22).

Existiera o no ${ }^{7}$, lo que nos interesa es la constitución del personaje mismo. Por todo esto, quizá tendríamos que desconfiar de los datos recogidos en el prólogo en tanto responden a lo que hoy se denominaría forma literaria, esto es, a un topoi que sería propio del "chivalric prose romance" en el siglo XIII, por ejemplo. Más que inferir de esas líneas la existencia de un autor real, estas podrían ser entendidas como un mecanismo discursivo ficticio para construir un personaje, que, en todo caso, proporcionará un hilo y seguro una

${ }^{7}$ Otros críticos iniciaron una labor detectivesca que los llevó a certificar la existencia de un "John Mandeville" y a confirmar ciertos datos del texto, si bien la incidencia o función de los mismos en el libro es dudosa. En esta parte de la crítica se sitúa Marie-José LEMARCHAND, quien defiende la veracidad del viaje del autor asegurando que "junto a fuentes librescas, el texto contiene unas descripciones y unos relatos que no tienen referencia en ningún otro texto...", asî́ como la identidad del personaje: "En cuanto al carácter ficticio de su identidad, es absolutamente inconcebible que sea espuria y engañosa la confesión de autoría que, a modo de testamento y en el estilo notarial propio de esos documentos, hace el susodicho caballero Mandeville, al final de su libro, encomendándose a Dios..." y concluye de este modo su aseveración respondiendo: “¿Por qué no cabe la impostura? Simplemente, porque con las cosas del Juicio Final no cabría jugada ni blasfemia para ningún hombre del Medievo". (pp. 24-27 de la citada edición). En realidad, sólo serían hipótesis enfrentadas, polarizadas, a partir de las cuales se ha organizado la crítica mandevilliana y que van desde la acusación (por mentiroso, fraude o plagiario) hasta los intentos por "rescatar" al autor, etc. 
$v o z$ al relato. Este mecanismo se asemeja a una fórmula cuasi jurídica y, a partir de él, el lector (u oyente) lee otros datos, recibe una información que va más allá de los hechos concretos que podríamos comentar hoy. Como señala I. M. Higgins ${ }^{8}, 1322$, la fecha de partida (y el día de San Miguel remite a la sacralización del tiempo), pese a no coincidir con hechos históricos relevantes, implica que el personaje, al haber estado tanto tiempo fuera de lo que se consideraba la Cristiandad, le permiten una posición más o menos cómoda para establecer cierta crítica; Saint Albans, por ejemplo, significa que el lugar de nacimiento está ligado a una abadía importante en la que el personaje pudo haber aprendido o recibido la educación que le permite las diversas citas latinas de las Escrituras, etc. Es decir, toda esa información del prólogo significa, pero dentro de un orden o código distinto al que normalmente se ha recurrido para descifrarlo, significa históricamente.

No vamos a incidir más en la cuestión del autor, que es una de las más debatidas y que ha polarizado la inmensa mayoría de los acercamientos críticos a Los viajes... Para nosotras lo productivo del prólogo consiste en haber creado un personaje, Sir John Mandeville, que cuenta, describe un viaje, ficticio, a través del oriente con dos centros bien delimitados: Jerusalén en la primera parte y lo que se denominan las lejanas tierras de Ultramar (Asia Oriental) en la segunda, es decir, primero una peregrinación y después una ruta (a nuestro parecer, la parte del libro en la que el texto alcanza más dinamismo y agilidad), caracterizada por intereses sacralizados pero también mercantiles y curiosos.

Habría que analizar si realmente estamos ante un libro de viajes en sentido estricto o qué se entiende por este, por cuanto constituye otro de los problemas o dificultades para la recepción del texto. De esta forma, no estaríamos ante una guía que proporciona consejos prácticos a los viajeros (aunque así fue leído en los primeros momentos: así Colón o antes el mismo Juan I, que intentó obtener el libro a toda costa por los datos útiles que contenía); porque la primera dificultad residiría en la definición del término viaje: de acuerdo con la definición del diccionario normativo significa 'traslado, desplazamiento, recorrido', pero si pretendiéramos determinar si

${ }^{8}$ Iain MaCleod HigGins, Writing East: The "Travels" of Sir John Mandeville, Philadelphia, $\mathrm{U}$ of Pennsylvania P, 1997, pp. 52-53. 
existe un tipo de discurso o un género de viajes, qué formaría parte de él o qué textos se inscribirían en él: aquellos que tienen sentido real, esto es, se ajustan a la verdad histórica, o también los que plantean un sentido metafórico, más o menos verosímil. Y es que este tipo textual es mudable, confuso, de límites poco claros, constantemente perdidos en la frontera del relato: descripción de lugares explorados o instrumentos de información, fiabilidad, eficacia, el otro, el lugar otro, interior / exterior, aquí / allí, etc. son cuestiones que se plantean incluso al margen del saber o del conocimiento, puesto que un texto de ficción puede releerlas desde puntos de vista diferentes ${ }^{9}$.

Tamarah Kohanski en What is a 'travel book' anyway?: Generic Criticism and Mandeville's Travels afirma que Los viajes de Sir John Mandeville no es un libro de viajes en absoluto:

[...] at least not in the limited and limiting sense the early critics imply by this term [...] The Travels is not easily reducible to a single label but rather is a genericlly complex work. An understading of the book's generic complexity must be central to any effort to better understand and appreciate it, to go beyond the early critics' sense of the work as a self-conscious lie masquerading as a "real travel book", and to read it as a work of some literary merit that exists more in the spaces between our familiar categories of writing than within a single ill-defined genre. (p. 117)

Definir los límites del supuesto género "literatura de viajes" es claramente problemático. Kohanski, por ejemplo, recurre a Percy Adams ${ }^{10}$, según el cual definir la literatura de viaje (le récit de voyage) es imposible. De hecho, no es un género o subgénero incardinado dentro de la categoría de historia, como bibliotecarios e historiadores han dicho con frecuencia; ni tampoco es una rama de la historia más que lo es de la geografía; por

${ }^{9}$ Por eso, el italianista Luigi Monga propone el término hodopórica, literalmente, 'relacionado con el viaje', para referirse a este corpus textual tan amplio y ambiguo, una especie de definición elíptica puesto que precisamente elide el término ciencia que originariamente los precedía. Para la complejidad etimológica de viajar, partir, volver, etc. vid. Domenico NUCERA, Los viajes y la literatura, en Armando GNISCI ed., Introducción a la literatura comparada, Barcelona, Crítica, 2002, especialmente p. 247 y ss,

${ }^{10}$ Percy G. ADAMS, Travelers and Travel Liars 1660-1800, New York, Dover, 1980 (Primera edición en 1962, la que cita es una reimpresión). 
supuesto, está vinculado a la geografía y a la historia, pero, en todo caso, la "subjetividad" es otra. Adams afirma:

Travel literature covers a range of material and comes in a wide variety of forms, including guides, notes, letters, dictations, diaries, simple first or third person narratives, poems, and even dialogues (Adams, $42 \mathrm{ff}$.), citado por Kohanski en p. 119.

Por eso, Kohanski concluye afirmando que definir Los viajes de Sir John Mandeville como libro de viaje es casi no decir nada, porque los libros de viajes son tan variados en la forma, aproximación, técnica narrativa, contenido, etc, que el término "travel book" no da guidelines for our thinking.

En todo caso, la crítica academicista exige una clasificación, aunque sólo sea como aproximación metodológica. Por eso habría que tener en cuenta a Jauss, para quien cada libro sería una concretización (un producto concreto) único. Kohanski, siguiendo precisamente a Jauss, sugiere:

If we are to read the book well, then, we must remain open to it: we err if we reduce our expectations of the Travels to a level of generic simplicity that does not do justice to all its parts. If we read the Travels as "satire" or "propaganda" or even as "guidebook/itinerary" or "travel romance", we close our minds to much that the work has to offer us. Similarly if we read it as rigidly defined history - which corresponds to the traditional view of the travel-book form, the work as factual narration of real events- we have seen in the work of the early critics how badly we can go astray. In the best and freest of reading situations, we the informed, practiced readers use our generic expectations as guidelines, a context, a framework for our perceptions, constantly revising those expectations as we read to fit with what we see in the text. But that is not always the way it works. In the worst case, we bombard the text with our expectations, alloing no room for development over the course of our reading. (p. 127) 
En cuanto a su unidad o estructura, se ha dicho ${ }^{11}$ que es un "guidebook / itinerary" (R. Hanna), es decir, a medio camino entra la guía para peregrinos y la narrativa de un itinerario sin más; también que vendría a constituir un nuevo tipo de género llamado travel romance (J. Bennet), cuya novedad fundamental residiría en basarse en la geografía más que en una historia fabulosa, como hacían los romances; y hasta se ha afirmado que el travel book (M. Campbell) es un género multigenérico. Más allá de estos intentos de explicación, el modelo básico en que se apoya Los viajes de Sir John Mandeville es el Libro por excelencia, esto es, la Biblia, algo evidente en la Edad Media, pero que a veces se ha perdido de vista en este tipo de acercamientos. La legitimidad del texto es la del Libro Sagrado; por eso, no es que estemos ante un texto religioso cuyo objetivo fundamental es la propaganda, sino que se trata de un libro sacralizado a mediados del siglo XIV que se configura estructuralmente como summa. Se ha querido leer a lo largo del texto y, dadas las características de su composición, una tendencia incipientemente humanista. Así, la imagen de un escritor sentado a la mesa con todos los instrumentos de escritura necesarios y, sobre todo, con una biblioteca a su disposición (que incluía los libros de viajeros más significativos hasta la fecha) ha servido para hablar del autor John Mandeville como un humanista adelantado, un poco al modo de Petrarca, que es capaz de crear, sin moverse de su casa, un mundo ficticio perfectamente documentado. Donald R. Howard ${ }^{12}$ habla de Mandeville-autor en términos de enciclopedista y estudioso y afirma:

He mastered an imposing amount of written matter, organized it in an original form, and presented it in a thoughtful, imaginative way that might as well be called artistic. A travel book based on learning rather than personal experience sounds like the undertaking of a humanist, and as we have seen, Petrarch himself made such an undertaking. With this in mind

${ }^{11}$ Mary B. CAMPBELL, The Witness and the Other World: Exotic European Travel Writing, 400-1600, Ithaca, New York, Cornell University Press, 1988; Ralph HANNA, Mandeville, in A.S.G. EDwARDS ed., Middle English Prose: A Critical Guide to Major Authors and Genres, New Brunswick, N. J., Rutgers University Press, 1984, pp. 121-132; Josephine W. BENNET, The Rediscovery of Sir John Mandeville, New York, MLA, 1954. (Modern Language Association of America Monograph Series 19).

${ }^{12}$ Donald R. HOWARD: "Mandeville's Travels”, in Writers and Pilgrims: Medieval Pilgrimage Narratives and Their Posterity, Berkeley, Univ. of California, 1980, pp. 53-76. 


\begin{abstract}
Zacher argues that Mandeville's "curiosity" is historically akin to the intellectual pursuits and exploratory voyages of Renaissance men: he sees in the plan of the work an embodiment of the historical movement from medieval pilgrimage to Renaisance voyage, and finds in Mandeville an inclination like Petrarch's "to make many brief visitation with maps, and books, and imagination. (pp. 55-56)
\end{abstract}

En su trabajo, Howard, por un lado, se basa en la tradición academicista que ha relegado el libro de Mandeville al olvido y, por otro, intenta "salvar" a Mandeville por su actitud humanista (o sea, un caso típico de adelantado a su tiempo y, por tanto, sin más remisión, incomprendido), es decir, de la peregrinación al viaje renacentista. Sin embargo, no se trata tanto de un esfuerzo de imaginación por parte del supuesto autor de Los viajes... en el que construye un "nuevo mundo" a partir de la autoridad de fuentes anteriores, cuanto del establecimiento de un itinerario: en realidad, el único posible dentro del marco feudal sacralizado, es decir, Jerusalén en última instancia. Por eso, la primera parte del texto mandevilliano es la que más nos interesa: el objeto último del viaje es el que todo buen cristiano debía tener, esto es, la peregrinación y la idea de cruzada que subyace en última instancia. Así se explicita al comienzo, en la carta dedicada al lector:

..Muchos libros se podrían contar destos, y uno dellos y no de los peores, es este Itinerario de Mandevilla que casi no leya nadie por ser antiguo, y casi no parecia ninguno por aver muchos dias que se imprimio. Siendo por cierto digno que se lea y se goze de tanta variedad y tanta noticia de cosas peregrinas como contiene. (Ed. de M.J. LEMARCHAND, p. 78)

Y en el Proemio donde a propósito de Tierra Santa dice el texto:

Amable y generosa es esa tierra, sembrada y regada por la sangre de Cristo. Es llamada Tierra de Promisión, porque a la hora de su muerte nos prometió heredarla, como hijos suyos. Por lo tanto, todo buen cristiano que tenga poder y fortuna debe luchar por reconquistar esta legítima herencia, arrancársela a los infieles y apropiársela. Nuestro nombre de cristianos viene de Cristo, nuestro Padre, y puesto que somos hijos de Dios, tenemos que reclamar y quitar de manos extranjeras la herencia que Él nos dejó. (Ed. de LEMARCHAND, p. 81) 
Este Oriente (el más cercano) no puede ser entendido más que a partir de los conceptos conocidos. La mirada del personaje Sir John, entonces, no descubre el Oriente, sino que lo reformula: no se puede ver aquello para lo que no se está preparado (es lo que le ocurriría más tarde a Colón, por ejemplo). La mirada, entonces, está condicionada por el mundo conocido, por lo que se sabe del mundo (a través de libros, etc.). Las cosas que se ven afuera son distintas de las que esperamos ver en casa (y aquí coincidimos con Howard), pero estarían igualmente tipificadas a priori (por toda esa narración de viajes, etc.). Por eso, tampoco era necesaria la presencia en todos los lugares descritos, no hacía falta ir porque se contaba con la información suficiente (otros libros, es decir, la experiencia ajena en forma de auctoritas): de ahí que el mundo descrito en los primeros capítulos sea absolutamente bíblico. Jerusalén - que, por otra parte, está ligada al Paraíso a través de multitud de referencias a lo largo del libro- constituye el centro del mundo y toda la cartografía mandevilliana procede del libro Sagrado, nada extraño si tenemos en cuenta que para la configuración misma de los mapas el modelo utilizado era el mismo. Pero es que, además, el personaje Sir John ofrece una demostración (en el capítulo 21, de la edición de Ana Pinto, al que luego volveremos):

\begin{abstract}
Me habéis oído decir que Jerusalén se encuentra en el centro del mundo, cosa que se puede demostrar y comprobar así: si se clava una espada recta dentro de la tierra a mediodía en el equinoccio, la espada no proyectará su sombra hacia ningún lado. De que Jerusalén está en el centro del mundo da testimonio David en el salterio donde dice: Deus operatus est salutem in medio terre [Dios obró la salvación en medio del mundo]. (p. 213)
\end{abstract}

¿Qué ve el supuesto viajero o qué puede ver? La cartografía se adecua al concepto bíblico, y, aún así, pretende ser tomada como hecho objetivo cierto a partir del cual basar una navegación o viaje. En la geografía mandevilliana, entonces, se acomodan los distintos hitos registrados en la Biblia como si de verdades históricas se tratasen, porque ésa era la verdad del mundo conocido. A través del itinerario (descrito con extremada minuciosidad) por Constantinopla, Egipto y Tierra Santa, el personaje Sir John, caballero como se dice en el prólogo, se convertirá en un peregrino más. El tópico que funciona en este caso es el del homo viator. Sir John es un "hombre que viaja". Esta expresión debe entenderse dentro de un contexto 
mental muy diferente de lo que fue a partir del siglo XVII. Las lenguas romances han empleado palabras derivadas formalmente del latín viare o viaticum, es decir, viaje, viaggio, voyage. Sin embargo, desde el punto de vista semántico este conjunto léxico corresponde al término latino itinerarium y remite a la idea de caminar, de espacio que queda por recorrer. Así, el viaje pone en marcha la capacidad para cruzar un límite, para afrontar una alteridad. La idea del viaje manifiesta la tendencia al desplazamiento, da una perspectiva de movilidad que, a la vez, es un deseo de conocimiento. Desde finales del siglo XII, se conservan textos en los que los viajeros utilizan términos que significan preguntar (una información), aprender (un hecho nuevo), descubrir (a veces las metáforas místicas son decisivas, por ejemplo de San Buenaventura que hacia el año 1270 escribe Itinerarium mentis in Deum, que podríamos traducir Viaje del espíritu hacia Dios) ${ }^{13}$. Y es que el viajero concibe su deseo de cambio, su insatisfacción difusa, su negativa a permanecer o, más exactamente, demorar, como una aspiración a la sabiduría. Estamos muy lejos del viaje actual en el que se borran el sujeto y el objeto, aquí sólo queda un trayecto puro y simple: el actual turismo. Pero la Edad Media ignoró completamente esta situación: el hombre cruzaba el espacio pagando en tiempo, de aquí la representación de conjunto del espacio recorrido. Por eso, el viaje medieval aparece siempre como maravilloso: es lo que significan siempre las curiosidades que jalonan el itinerario. Así, en Los viajes de Sir John Mandeville (como años antes en el texto de Marco Polo) el viaje tiene una existencia triple: desplazamiento espacial, agotamiento del tiempo e iniciación de los mitos fundadores. En este sentido, el texto supone la posibilidad de someter el espacio a la razón.

En realidad, Los viajes de Sir John Mandeville (como antes Libro de las Maravillas, de Marco Polo) está trazando las formas de una espacialidad con las que se construye el sentido mismo de la existencia. El espacio, así, no se ofrece como una estructura geométrica: en el espacio geográfico, el problema de la mirada va más allá del desplazamiento, del límite para ir de un punto a otro y se convierte en espacio vivido, se construye a través de una trayectoria que presenta su propia historicidad, un espacio como signo de

\footnotetext{
${ }^{13}$ Para estas precisiones, vid. Paul ZuMTHOR, La medida del mundo. La representación del espacio en la Edad Media, Madrid, Cátedra, 1994, p. 178 y ss. 
poder y la seguridad que ofrece este espacio reside en la articulación del espacio próximo y el lejano, y, de este modo, se puede cargar de amenazas, de peligros repentinos, de irrupciones, de singularidades y de mirabilia. En este sentido es esclarecedor el aviso del impresor que abre la segunda parte del libro:

En aqueste Segundo Libro se trata de muchas y diversas cosas que son por el mundo repartidas: y porque especialmente en las tierras de la Yndia ay muchas admirables cosas, quasi impossibles de creer, pareciome a mi imprimiendo la presente obra que entre las otras cosas que en el presente libro ay de maravillar, es aver hombres de tal manera producidos... (p. 173, edición de LEMARCHAND)

A esta espacialidad de la que venimos hablando, podemos añadir lo que supuso el Mediterráneo en sí mismo como espacio, como encrucijada entre las más diversas civilizaciones. Unido así a la propia concepción medieval del mundo, surge la leyenda, el mito, a medio camino entre la historia y el discurso literario. Más fascinantes que lo real, las leyendas cautivaban desde antiguo en su oralidad a quienes las escuchaban. De Oriente llegaban historias enigmáticas, increíbles, que poseían al público oyente que, por su desconocimiento, su lejanía, acababa por creer ciegamente en esos extraños mundos donde tenían cabida las más extraordinarias de las criaturas o los parajes más sorprendentes.

Toda esta tradición se deja latir en Los viajes... desde la cosmografía, a ciudades tan simbólicas como Babilonia, Damasco, El Cairo..., descritas en la primera parte, las islas ${ }^{14}$, que se enumeran en la segunda, hacen de los mirabilia el ámbito perfecto para disfrazarla de milagros. Así sucede con el mito del Ave Fénix (cap. VIII) que cristianiza, la maravilla que tiene lugar en la isla de Calanoc, en la que aparecen los peces como símbolo de la cristología:

\footnotetext{
${ }^{14}$ Para el papel que juegan las islas como elementos marítimos maravillosos que propician lo sobrenatural y extraordinario, y como motivo recurrente en los libros de viaje y de caballerías, nos remitimos a C. SORIANO, Angliaterra, tierra de maravillas en el Victorial, en Juan PAREDES ed.: Medievo y Literatura IV. Actas del "V Congreso de la Asociación Hispánica de Literatura Medieval (Granada, 27 septiembre- $1^{\circ}$ octubre 1993)" Granada, Universidad de Granada, 1995, pp. 351-371.
} 
Existe en esta isla una gran maravilla que no se encuentra en ningún otro lugar. Una vez al año, todos los peces llegan a la orilla y, una especie tras otra, hacen reverencia, de tal forma que sólo se ven peces y casi se deja de ver el mar. Allí se quedan durante tres días, y los isleños cogen tantos como quieren. (cap. XXIII, p. 203, ed. de LEMARCHAND)

O la maravilla que acontece en el Valle Peligroso situado en la isla de Latona (cap. XXXII).

Una novedad radical de Los viajes... es el concepto de esfericidad de la tierra. Antes de la difusión de las teorías ptolomeicas al respecto, el texto mandevilliano propone un concepto nuevo y lo justifica. El capítulo clave, en este sentido, es el número 21: DE LAS VILES COSTUMBRES QUE IMPERAN EN LA ISLA DE LAMARY Y DE CÓMO LA TIERRA Y EL MAR TIENEN FORMA REDONDA, POR LA PRUEBA DE LA ESTRELA LLAMADA ANTÁRTICA QUE ESTÁ FIJA EN EL SuR. Después de explicar las costumbres de los autóctonos (ir desnudos por el extremo calor; la ausencia de la institución matrimonial y las consecuencias que ello implica para la organización social: mujeres comunes; propiedad común y rotativa y, por tanto, ausencia de clases sociales; todo eso frente a la única costumbre "terrible": el canibalismo), se refiere a las dos únicas estrellas "fijas" en el firmamento: la Estrella Tramontana (Estrella Polar), que indica el Norte, y la Estrella Antártica, que indicaría el Sur. La primera es la que puede verse desde Occidente; la segunda sólo se vería en estos territorios que empieza a describir. Por tanto:

De todo esto se puede deducir bien que el mundo es redondo, pues la parte del firmamento que aparece en unos países no es la misma que la que aparece en otros. Esto cualquiera lo puede comprobar valiéndose de la experiencia y el razonamiento ya que, si se encontrasen barcos dispuestos a recorrer el mundo, podría recorrerlo entero, desde arriba hasta abajo. Todo esto lo he comprobado después de lo que he visto, pues he estado en Brabante y he observado en el astrolabio que la estrella llamada Tramontana está a cincuenta y tres grados de altura, mientras que en Alemania o Bohemia está un poco más lejos, a cincuenta y ocho grados; y más hacia el norte está a sesenta y dos grados y unos cuantos minutos de altura. Todo esto lo he visto reflejado en el Astrolabio. Sabed que frente a la Estrella Tramontana se encuentra la otra estrella llamada Antártica, la que antes he mencionado. Estas dos estrellas no se mueven jamás y alrededor de ellas gira todo el firmamento, lo mismo que una rueda gira en torno a su eje. 
[...] Del firmamento he visto, pues, tres cuartas partes y cinco grados y medio. Por todo lo cual, os aseguro que un hombre podría circunnavegar toda la tierra de todo el mundo, tanto por arriba como por abajo, y regresar a su país, si tuviera compañía, embarcación y guía. Siempre encontraría gentes, tierras e islas, lo mismo que sucede en este país[...] Todas las partes del mar y de la tierra tienen sus partes contrarias habitables y accesibles, tanto las de esta parte [Occidente] como las de la de allá [Oriente] ${ }^{15}$. (pp. 210-212, ed. de Ana PINTO)

Este concepto, más o menos novedoso en un texto de estas características, será decisivo para comprender la influencia que Los viajes de Sir John Mandeville ejerció, no tanto en la llamada literatura posterior (concepto discutible), cuanto en el imaginario de otros ilustres viajeros. El caso más representativo quizá sea el de Cristóbal Colón, del que sabemos que manejó el texto mandevilliano (así como el Libro de las Maravillas, de Marco Polo). De hecho, desde el prólogo, y como hemos visto en este ejemplo citado, el personaje mandevilliano se esfuerza por situar su discurso dentro de los parámetros de la verdad. Esta verdad, que se ancla desde el primer momento en el modelo bíblico, como decíamos, se ratifica insistentemente en todo el libro a través de las alusiones reiterativas tanto al concepto de auctoritas (ya sea de los sabios del pasado o sus libros) como al hecho decisivo de la experiencia personal (el protagonista dice que sabe todo eso porque estuvo allí y lo vio). Y esto a través de la descripción, fundamentalmente. Según Zumthor, a medida que los textos son más elaborados y avanzando en el tiempo, hay un intento hacia la construcción de una retórica particular y empiezan a constituirse una serie de topoi ("what I say here is not taught in the schools"; "this is what I witness"), habría una suerte de técnicas privilegiadas (hipérbole, exclamación, enumeración y otras) junto a otros

\footnotetext{
${ }^{15}$ Después de todo este despliegue de conocimiento, el personaje Sir John advierte:"Y aunque es posible circunnavegar el orbe entero, sin embargo, sólo uno entre mil sería capaz de volver al punto de origen, pues debido a la inmensidad de la tierra y del mar se pueden tomar miles y miles de rutas. Pero nadie sabría dar con la ruta acertada para volver al punto de origen, si no fuese por casualidad o por obra de la gracia de Dios, porque la tierra es muy grande; su circunferencia mide 20.425 millas, según la opinión de los sabios astrónomos del pasado, a los que no contradigo; pero a mí me parece, y lo digo con todo respeto, que la circunferencia es mayor" (p. 214). En este fragmento, además, se concentran dos de las características básicas del personaje mandevilliano: el hecho de acudir a la auctoritas para validar su conocimiento por una parte; pero, también y especialmente, basarse en la supuesta experiencia. La combinación de ambas resultaría, pues, decisiva para la construcción de su discurso.
} 
elementos retóricos "decorativos" (la partida, la duración del viaje, el país desconocido, la bienvenida o el rechazo, etc.). En "The Medieval Travel Narrative" ${ }^{16}$, el crítico canadiense afirma:

For the one who narrates his voyage, this narrative (by pen or by mouth) achieves his reintegration into the familiar world from which he set off. But also, the principal aim here is less to analyze the reality of the voyage than to prolong the experience of it. However (because such are the methods of the discourse), description, until the fifteenth and sixteenth centuries, proceeds in general by "common-places" (based on the book knowledge we have of the earth) rather than by "naïve" notations; description thus remains poor in concrete detail and is often organized along the lines of an actual itinerary; it is cut, and, as it were, distorted by anecdotal digressions. (p. 812)

Es decir, la descripción funciona en el texto mandevilliano a partir de lugares comunes basados en el conocimiento libresco preexistente más que en la presencia efectiva en los lugares que se intenta describir o dar a conocer al público.

De acuerdo con Paul Zumthor, habría una característica básica, identificable en el texto que nos ocupa, que tiene que ver con la fascinación: la fascinación de un orden espacial, la comprensión de lo que es una experiencia de lo otro... La verdad ofrecida o construida en Los viajes de Sir John Mandeville implica revisar todo el pensamiento anterior sobre el Oriente. Asumir la diferencia, la imagen de lo Otro significa asumir un espacio ficticio y nombrarlo. Probablemente tenga razón Edward W. Said ${ }^{17}$ cuando, en su famoso ensayo Orientalismo, afirmaba: "El orientalismo expresa y representa, desde un punto de vista cultural e incluso ideológico esa parte como un modo de discurso que se apoya en unas instituciones, un vocabulario, unas enseñanzas, unas imágenes, unas doctrinas e incluso unas burocracias y estilos coloniales". Por eso, más adelante puede afirmar, siguiendo a Foucault, que "Oriente es una idea que tiene una historia, una tradición de pensamiento, unas imágenes y un vocabulario que le han dado una realidad y una presencia

\footnotetext{
${ }^{16}$ Paul Zumthor, The Medieval Travel Narrative, "New Literary History", 25, $\mathrm{n}^{\mathrm{o}} .4,25^{\text {th }}$ Anniversary Issue (Part 2) (Autumn, 1994), pp. 809-824.

${ }^{17}$ Edward W. SAID, Orientalismo, Madrid, Libertarias / Prodhufi, 1990, p. 20 y ss.
} 
en y para occidente. Las dos entidades geográficas, pues, se apoyan y hasta cierto punto se reflejan la una en la otra". (p. 23)

La Otredad en Los viajes... funciona (y en esto la crítica suele coincidir) como un espejo que proyecta un reflejo especial: ofrece una mirada crítica. La contemplación o descripción de tierras lejanas propicia que la mirada se vuelva hacia dentro, es decir, el Otro importa en tanto ofrece una reflexión. Para el personaje Sir John, en la mayoría de los casos, ese Otro no interesa en sí, sino por cuanto constituye un reflejo de los defectos propios. Relevante al respecto es el capítulo XVII, titulado: De la religión y las costumbres de los sarracenos. En él, a propósito de una entrevista que mantiene Mandeville con el sultán, reprocha y adoctrina:

\begin{abstract}
Os voy a contar precisamente lo que me dijo al respecto el propio sultán, un día que mandó salir a todos de su cámara, porque quería quedarse a solas conmigo y tener conmigo consejo. Así que me preguntó cómo se comportaban los cristianos en nuestro país. «Bien, gracias a Dios», contesté. Entonces me replicó: «Esto no es verdad: vuestros señores y flámenes no se preocupan para nada de servir a Dios. Ellos, que tendrían que dar ejemplo del bien al pueblo, son precisamente los que peor obran... Sabemos con toda seguridad que cuando servís bien a vuestro Dios, Él viene a ayudaros y entonces nada ni nadie se os resiste. También sabemos, por las profecías, que los cristianos volverán a conquistar Tierra Santa, cuando sirvan mejor a su Dios, pero por ahora, su vida es tan lamentable que no tenemos ningún temor a que Dios venga a ayudarlos, que no vendrá»... ¿No resulta escandaloso para nuestra fe cristiana que unas gentes sin fe ni ley puedan reprendernos así? (pp. 167-169, ed. de LEMARCHAND)
\end{abstract}

El objetivo con el viaje es, en cierto modo, reconvenir a la cristiandad. No sólo la peregrinación es un deber de todo cristiano, sino, especialmente, la propagación del cristianismo. El lugar propicio para ello era Asia, Oriente, tierra de infieles y bárbaros. La curiosidad mostrada por el personaje tiene que ver más con el conocimiento de este vasto territorio para dar ideas y exhortar al adoctrinamiento (de hecho ya desde el siglo XIII hay misioneros a los que se encarga esta labor). El problema que se planteaba era la imposibilidad de dicho objetivo dadas las circunstancias particulares del occidente cristiano en el siglo XIV, es decir, la división y las luchas e intrigas internas. No olvidemos que el siglo XIV es, además, el momento en que el cisma eclesiástico alcanza mayor relevancia: entre 1309 y 1378 la curia papal 
se establece oficialmente en Avignon, si bien Urbano V estuvo en Roma entre 1367 y 1370 en un intento por restablecer el papado; el gran cisma, además, tuvo lugar entre 1378 y 1417, y dividió Europa en dos bandos (a favor de Avignon o a favor de Roma; Inglaterra se decantó por Roma, mientras que Francia lo hizo por Avignon), como queda perfectamente establecido en el proemio (y a lo largo del texto):

Pero en estos tiempos nuestros, los corazones de los señores y castellanos se ven forzados por la codicia, la vanidad y la envidia que prefieren guerrear para despojar a otros de sus feudos que reconquistar su propia herencia. En cambio, la gente del pueblo, que sí estaría dispuesta a arriesgar sus vidas y sus bienes para reconquistar esa herencia nuestra, nada puede lograr sin sus señores, porque una asamblea popular sin un señor a la cabeza es como un rebaño de ovejas sin pastor, que se pierden y van errando, sin saber ni qué hacer ni adónde ir. Pero si a nuestro Santo Padre el Papa le pluguiese lograr la concordia entre los príncipes para que emprendieran con sus pueblos el santo viaje hasta Ultramar, estoy seguro de que la Tierra Prometida volvería rápidamente a ser cristiana y sería entregada a sus legítimos herederos, los de Jesucristo.(pp.81, ed. de LEMARCHAND)

La división es intolerable y, precisamente a través de la constatación de ciertos "otros" ordenados y unidos en tierras lejanas y bárbaras, es como podría resolverse esa situación.

\section{A MODO DE CONCLUSIÓN}

Esperamos haber ofrecido una visión más o menos amplia de lo que constituyó El Libro de las Maravillas del Mundo de Sir John Mandeville en su tiempo, elaborado dentro de una estructura única, propia de una determinada concepción del mundo.

A través de otra mirada, el espacio y la "extensión”, la imago mundi, aparece (se visualiza) como única. La tierra como centro y la vida como un orden que plasma un universo ceistianizado. No se percibe el tiempo, sino un 
espacio que no es abstracto ni homogéneo, sino concreto e individual ${ }^{18}$. De ahí que la representación de ese espacio, siempre simbólico, que percibe el hombre medieval, y de ese lugar que ocupa en el cosmos a imagen y semejanza de un universo en miniatura, no tenga otra forma de reflejarse que a través del movimiento, del viaje.

El espacio inquieta al hombre y es esa inquietud la que lo lleva a descubrir nuevos caminos. Ya sea como portador de la Santa Cruz, como peregrino en busca de recompensa espiritual y purificación para su viaje al Más Allá, o como mercader que cruza el Mediterráneo en busca de las sedas y especias más deseadas, el espacio, y más aún, el espacio social generador de mitos, en el que opera la imaginación y la fantasía ${ }^{19}$, constituirá la base sobre la que se asentarán, como discurso literario, Los Viajes del caballero Sir John Mandeville y en el que se inscribe la noción de esfera como categoría privilegiada en la que confluyen la relación, la conexión, la fluctuación de un dentro-de y en-un-con algo que explicita la historia de la escritura como historia de la fluctuación historicista en la que no estamos nunca en-el-mundo sino en la burbuja espacial de la historia.

${ }^{18}$ P. ZUMTHOR, La medida del mundo, op.cit., p. 36 y ss. De su estudio introductorio seguimos los conceptos sobre el espacio y el movimiento, o lo que llama nomadismo.

${ }^{19} \mathrm{P}$. Zumthor, La medida del mundo, op. cit. p. 17. 